\title{
Isolated Caeco-Vesical Fistula: A Case Report
}

\author{
Lucienne Irène Patricia Ondima ${ }^{1,2^{*}}$, Melvin Ondongo Atipo ${ }^{1,3}$, Steve Aristide Ondziel Opara ${ }^{1,3}$, \\ Didace Massamba-Miabaou,4, Régis Moyikoua1,5, Peggy Dalhia Galou Mawandza1,6, \\ Moïse Yanguedet Service², Caryne Mboutol-Mandavo ${ }^{1,2}$, Pierre Aymar Oko1,7, \\ Jean-Claude Mieret ${ }^{2}$, Cardinale Princilia Okiemy Niendet ${ }^{2}$, Gracia Christelle Ossete ${ }^{2}$, \\ Erica Nuptia Akobande², Anani Wenceslas Séverin Odzébé1,3, Prosper Bouya ${ }^{1,3}$
}

\footnotetext{
${ }^{1}$ Faculty of Health Sciences, Marien Ngouabi University, Brazzaville, Republic of Congo

${ }^{2}$ Pediatric Surgery Department, University Hospital Center, Brazzaville, Republic of Congo

${ }^{3}$ Urology and Andrology Department, University Hospital Center, Brazzaville, Republic of Congo

${ }^{4}$ Visceral Surgery Department, University Hospital Center, Brazzaville, Republic of Congo

${ }^{5}$ Medical Imaging Department, University Hospital Center, Brazzaville, Republic of Congo

${ }^{6}$ Multipurpose Resuscitation Department, University Hospital Center, Brazzaville, Republic of Congo

${ }^{7}$ Pediatric Intensive Care Unit, University Hospital Center, Brazzaville, Republic of Congo

Email: *ondimairene@gmail.com
}

How to cite this paper: Ondima, L.I.P., Atipo, M.O., Opara, S.A.O., Massamba-Miabaou, D., Moyikoua, R., Mawandza, P.D.G., Service, M.Y., Mboutol-Mandavo, C., Oko, P.A., Mieret, J.-C., Niendet, C.P.O., Ossete, G.C., Akobande, E.N., Odzébé, A.W.S. and Bouya, P. (2020) Isolated Caeco-Vesical Fistula: A Case Report. Open Journal of Urology, 10, 309-314.

https://doi.org/10.4236/oju.2020.1012036

Received: November 23, 2020

Accepted: December 28, 2020

Published: December 31, 2020

Copyright (c) 2020 by author(s) and Scientific Research Publishing Inc. This work is licensed under the Creative Commons Attribution International License (CC BY 4.0). http://creativecommons.org/licenses/by/4.0/

\section{Open Access}

\begin{abstract}
Congenital uro or genito-digestive fistulas are frequently found in the context of caudal pole malformations. Isolated congenital forms without associated anorectal malformation have not been reported until now. We report the first case we know a 9 year old female child received in a pediatric surgery consultation for fecaluria evolving since birth with a permeable anus. She presented a good general condition, a good staturo-ponderal and psychomotor development, a vulva soiled by stool and a permeable anus with a tonic sphincter. A retrograde urethrocystography revealed a caeco-vesical fistula. Surgery consisted of ligation-section of the caeco-vesical septum. A follow-up urethrocystography at three months post-surgery no longer visualized the fistula. Our post-operative follow-up is 4 years. Isolated congenital caeco-vesical fistula is an unknown pathology whose late diagnosis can have serious repercussions.
\end{abstract}

\section{Keywords}

Fistula, Congenital, Isolated, Caecum, Bladder, Child, Surgery

\section{Introduction}

Congenital uro or genito-digestive fistulas are frequently found in the context of malformations of the caudal pole (anorectal malformation, pouch colon, dupli- 
cation of the urethra, aphaly) [1] [2]. Congenital isolated forms without associated anorectal malformation such as isolated caeco-vesical fistula have so far not been reported. In acquired forms, they are of late diagnosis and are revealed by fecaluria. They are described in elderly patients and in particular pathologies such as Crohn's disease [3], colonic diverticulosis [4], caecal cancer [5], and more rarely intestinal amoebiasis [6], bladder bilharziasis [7] and intestinal hydatidosis [8], and even in these cases that caeco-vesical fistula remains exceptional. We report an observation of the first case, to our knowledge, of isolated congenital caeco-vesical fistula.

\section{Observation}

A 9-year-old girl is seen in a paediatric surgery consultation for fecaluria associated with a permeable anus which the parents had observed since birth. The late consultation is only justified by the pungent smell of urine soiled with almost permanent stool of the child who had her schooling interrupted. A notion of repeated urinary tract infections was signaled in her history. The girl was in good general condition, with normal staturo-ponderal and psychomotor development (Height: $145 \mathrm{~cm} /$ Weight: $35 \mathrm{~kg}$ ). There was a pungent smell of urine mixed with stool and coloured conjunctiva. The examination of the perineum revealed a stool-stained vulva, a wide urinary tract and an open vaginal orifice; a permeable anus with a tonic sphincter and a palpable stool-filled rectum.

The diagnosis was obtained by retrograde urethrocystography (UCR) which revealed a caeco-vesical fistula (Figure 1).

Following a water-soluble enema, it was possible to rule out recto-vaginal and recto-vesical fistula. Creatininaemia was normal. A week-long preoperative hospitalization was necessary for dietary management, colic draining by enemas and bladder asepsis (antibiotic therapy). A strict 72-hour diet resulted in clear urine with no microbial germs as confirmed by cytobacteriological examination. A standard preoperative assessment was carried out (complete blood count, hemostasis assessment and blood grouping).

The treatment was surgical with a right para-rectal approach, allowing an easy access to the caecum. During the exploration, we visualized the caeco-vesical septum (Figure 2) with an appendix passing underneath (Figure 3). The procedure consisted of the ligation-section of the caeco-vesical septum and an appendectomy of necessity (Figure 4).

The postoperative follow-up was simple with the resumption of the intestinal transit at day 4 , authorized feeding at day 5 , and the removal of the urinary catheter at day 8 post-surgery. The daily diuresis was $65 \mathrm{ml} /$ hour.

Anatomopathological analysis of the appendix revealed no abnormalities.

She was discharged 10 days after surgery. Clinical and biological follow-up (cytobacteriological examination of urine, creatininaemia) did not reveal any recurrence. A retrograde urethrography review at three months postoperative found no fistula (Figure 5). Our postoperative follow-up is 4 years. 


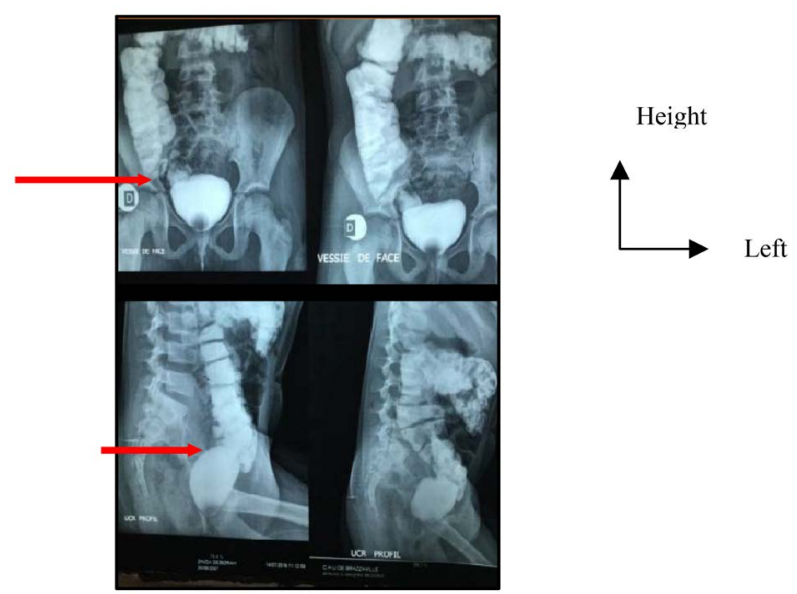

Figure 1. Retrograde urethrocystographyhighlightingthe fistula.
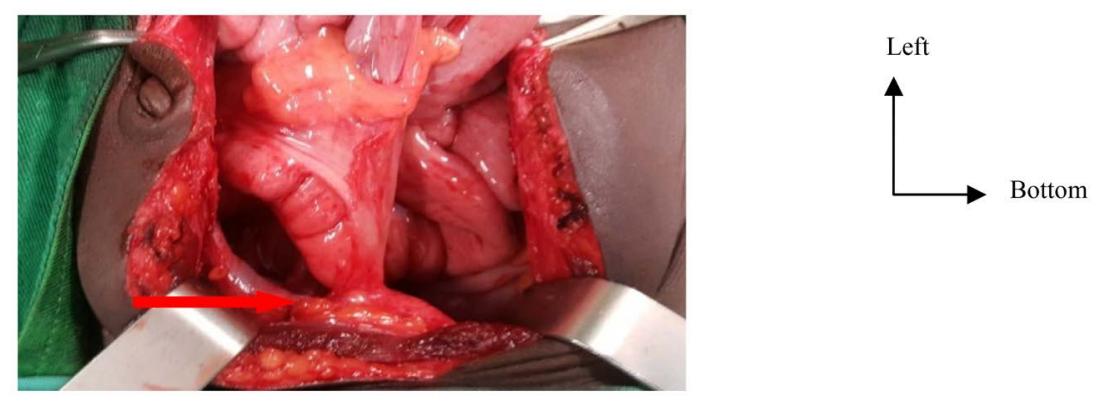

Figure 2. Caeco-vesical septum.

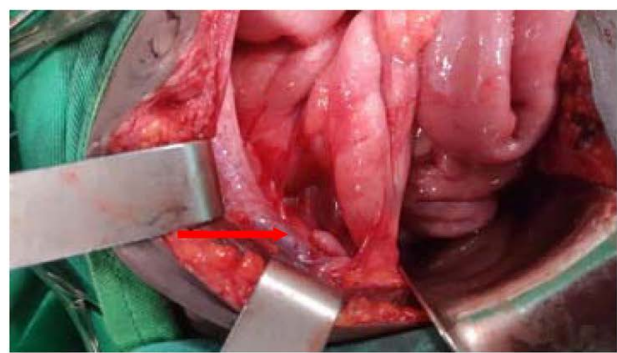

Figure 3. Appendixpassing underneath the caeco-vesical septum.

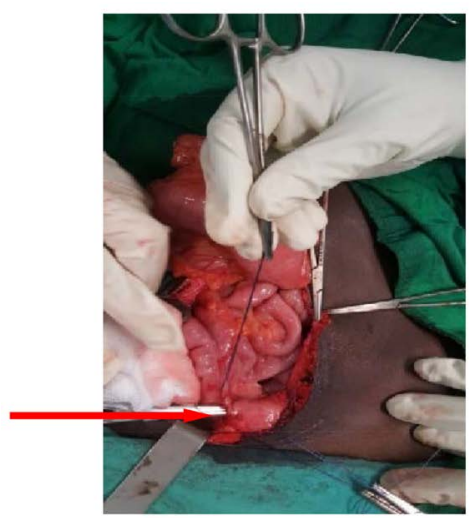

Left

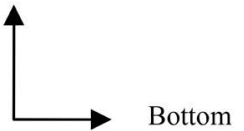

Figure 4. Sectionning of the septum and ligation of caecal and bladder banks. 

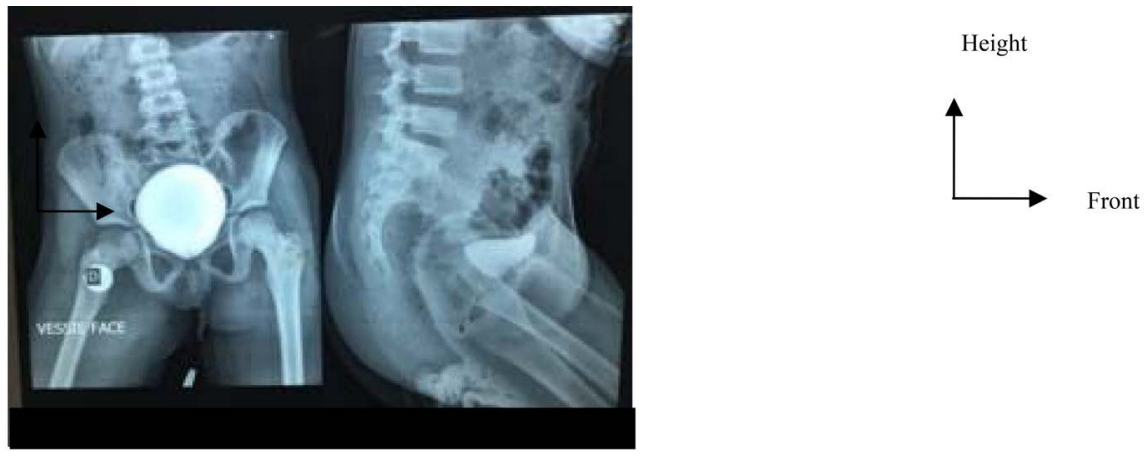

Figure 5. Retrograde urethrocystography 3 months post-surgery.

\section{Discussion}

Congenital uro-digestive fistulas are found in caudal pole malformations such as anorectal malformations and the pouch colon [1] [2]. Anorectal malformations are the most common congenital surgical abnormalities of the intestine. They occur in embryogenesis and in nearly $70 \%$ of cases are associated with other malformations (urogenital, musculoskeletal, cardiac, digestive and central nervous system) [9]. All forms exist, from fistula in situ to the total absence of the anus with or without urinary or genital fistula. The Peña classification [9] defines anorectal malformations as high or low depending on the position of the rectal cul-de-sac in relation to the supporting muscles and the level of a possible fistula. However, like the Krickenbeck classification [10], it does not describe a caeco-vesical fistula. This classification categorizes lesions in large clinical groups according to the location of the fistula (perineal, recto-urethral, recto-vesical, vestibular), cloacal and fistula-free lesions, and anal stenosis, as well as rare and regional variants such as the pouch colon, atresia or rectal stenosis, recto-vaginal fistula, the $\mathrm{H}$ fistula and others [10].

The pouch colon, in which a pocket-shaped dilation of a colon shortened by variable degrees is associated with an anorectal malformation, is a common anomaly in India. The pouch usually ends with fistula connecting to the genitourinary tract. In girls, the fistula leads either into the urethra or into the vestibule, and often a double vagina is found [1] [2]. It is currently classified as a rare regional variant of ano-rectal malformations [10]. Diagnostic confirmation is done through standard abdominal X-ray examinations without the need for enema [1] [2]. We found a permeable anus with a tonic sphincter; following a water-soluble enema it was possible to rule out a recto-vaginal or rectovesical fistula and colic pocket dilation, and hence an anorectal malformation or pouch colon. In our case, the isolated nature of caeco-vesical fistula is justified by the absence of other associated malformations and the confirmation by retrograde urethrocystography. We did not find an isolated cause of congenital caeco-vesical fistula.

Acquired entero-vesical fistulas are essentially the result of an inflammatory and infectious process of digestive origin, which will eventually develop into a 
fistula in a healthy bladder. Most often the intestine responsible is either the terminal ileum or the sigmoid. The two main etiologies of entero-vesical essentially colo-vesical fistulas, are sigmoidal diverticulosis [4] and Crohn's disease [3], which are found in the elderly. Sigmoidal diverticulosis is not in itself a disease, it is a hernia of the mucous membrane through the colon muscle wall. Its symptomatic form of complicated diverticulitis accounts for $40 \%-78 \%$ of the etiologies of colo-vesical fistula, with complications that can range from a simple peri-sigmoid abscess to the perforation of a diverticula in the large peritoneal cavity that causes generalized acute peritonitis, or in a neighbouring hollow organ, often giving a sigmoid-vesical fistula, or more rarely sigmoid-vaginal, sigmoid-ileal or even sigmoid-cutaneous fistula [4]. Clinical signs with type of pneumaturia and fecaluria are pathognomonic of the diagnosis. Crohn's disease is a chronic inflammatory bowel disease that can cause contiguous urinary tract damage, and responsible, though rarely, for entero-vesical fistulas [3]. In this case, we found a healthy colon. We did not perform any prior diagnostics, either urological or digestive, in the face of the findings of the radiological examinations and the difficulty of implementation in our center.

Caeco-vesical fistula in caecum cancer and intestinal amoebiasis are described in the elderly. Losco [5] describes a case of caecum cancer with caeco-vesical fistula in a 77-year-old patient with a history of endometrial cancer with hysterectomy and radiotherapy 18 years earlier. Vincent [6] describes the first case of caeco-vesical fistula due to a little-known and untreated intestinal amoebiasis in an 80-year-old patient in the form of acute peritonitis. Entero-vesical fistulas are exceptional in parasitic infections but can occur. Yddoussalah [7] describes the first case of vesico-sigmoidal fistula complicating bilharziasis in a 71-year-old patient, and Lahyani [8] the first case of vesico-sigmoidal fistula complicating intestinal hydatidosis in a 48-year-old patient. We did not perform biological tests for intestinal amoebiasis, urinary bilharziasis or hydatidosis, there being no anamnestic indication for these infections and because the symptomatology in our patient existed since birth. In urinary bilharziasis or hydatidosis, fistulas are essentially vesico-sigmoidal. Surgical treatment is done in a single operation after appropriate preparation of the colon [3] [11] except in emergency situations where a derivation in time is possible [5].

\section{Conclusion}

Isolated congenital caeco-vesical fistula is a little-known pathology yet of simple diagnosis and treatment. Late diagnosis has serious implications such as urogenital infections with the risk of long-term kidney failure and social isolation for the child.

\section{Parents Inform Consent}

We attest that the child's parents were informed and gave their accord for the publication of this case report. 


\section{Conflicts of Interest}

The authors declare no conflicts of interest regarding the publication of this paper.

\section{References}

[1] Chadha, R. and Khan, N.A. (2017) Congenital Pouch Colon. Journal of Indian Association of Pediatric Surgeon, 22, 69-78. https://doi.org/10.4103/jiaps.JIAPS 517

[2] Pandey, V., Gangopadhyay, A.N., Gupta, D.K. and Sharma, S.P. (2015) Single Stage Management of a Unique Variant of Congenital Pouch Colon with Triplet Fistula and Normal Anus. Journal of Indian Association of Pediatric Surgeons, 20, 148-149. https://doi.org/10.4103/0971-9261.154665

[3] Makni, A., Ahmed, S., Sami, K., Chebbi, F., Rebai, W., Ksantini, R., Fteriche, F., Jouini, M., Kacem, M., Azza, F., Safta, Z.B. and Makn, A. (2014) Surgical Treatment of Entero-Vesical Fistulas Secondary to Crohn Disease. La Tunisie Médicale, 92, 197-200.

[4] Anis, B.M. (2015) Colo-Vesical Fistulas of Diverticular Origin: 2 Case Reports. La Tunisie Chirurgicale, 25, 8-10.

[5] Giovanni, L. and Roger, R. (2007) Caecovesical Fistula. A Rare Manifestation of Carcinoma of Caecum. The New Zealand Medical Journal, 120, U2634.

[6] Vincent, P.J., Bhalla, V.P., Gill, M. and Salopal, T.K. (2000) A Case of Entero-Vesical Fistula. Medical Journal Armed Forces India, 56, 61-63.

https://doi.org/10.1016/S0377-1237(17)30097-7

[7] Yddoussalah, O., Saouli, A., El Ouazzani, H., Karmouni, T., Elkhader, K., Koutani, A., Andaloussi, A.I.A. and Mahassini, N. (2018) Vesico-Sigmoid Fistula Complicating a Bladder Bilharziasis: An Exceptional Case Report. African Journal of Urology, 24. 402-405. https://doi.org/10.1016/j.afju.2018.06.004

[8] Lahyani, M., Jabbour, Y., Karmouni, T., Elkhader, K., Koutani, A. and Andaloussi, A.I. (2014) Vesico-Sigmoid Fistula Complicating Intestinal Hydatidosis: About a Rare Case. The Pan African Medical Journal, 19, 117. https://doi.org/10.11604/pamj.2014.19.117.5220

[9] Le Bayon, A.G., Carpentier, E., Boscq, M., Lardy, H. and Sirnelli, D. (2010) Imaging of Anorectal Malformations in the Neonatal Period. Journal de Radiologie, 91, 475-483. https://doi.org/10.1016/S0221-0363(10)70062-7

[10] Hutson, J., Peña, A., Beket, E., Chatterjee, S., Coran, A., Davies, M., Georgeson, K., Grosfeld, J., Gupta, D., Iwai, N., Kluth, D., Martucciello, G., Moore, S., Rintala, R., Durham Smith, E., Sripathi, D.V., Stephens D. and Kunst, M. (2005) Preliminary Report on the International Conference for the Development of Standards for the Treatment of Anorectal Malformations. Journal of Pediatric Surgery, 40, 1521-1526. https://doi.org/10.1016/j.jpedsurg.2005.08.002

[11] Tiguert, R., Gheiler, E.L., Tefilli, M.V., Wood Jr, D.P. and Edson Pontes, P.J. (1998) Treatment of Colo-Vesical Fistulas in a Single Operation. Progress in Urology, 8, 507-510. 